\title{
Severe pulmonary hypertension and multiple left coronary arterial fistulas in association with congenital hepatic fibrosis
}

\author{
N G DEWHURST, N R COLLEDGE, H C MILLER \\ From the Department of Cardiology, The Royal Infirmary, Edinburgh
}

SUMMARY Multiple fistulous communications between the left anterior descending coronary artery and the left ventricle were found in a 55 year old woman with congenital hepatic fibrosis presenting with breathlessness. At cardiac catheterisation severe pulmonary hypertension was also found. In view of the persistent hypoprothrombinaemia, severe thrombocytopenia, and the multiple fistulas the risk of operation was thought to be unacceptable and she continues on medical treatment.

\section{Case report}

A 55 year old woman was referred to a respiratory diseases clinic because of increasing breathlessness and ankle swelling attributed to chronic bronchitis and cor pulmonale. There was a past history of congenital familial hepatic fibrosis (confirmed by liver biopsy eight years before) with autosomal recessive expression in other family members. She had smoked twenty cigarettes per day since the age of twelve. There was no relevant drug history and in particular no previous ingestion of anorectic agents. She complained of cough productive of mucoid sputum for five years.

She was obese $(80 \mathrm{~kg}, 1.57 \mathrm{~m})$. There was peripheral cyanosis but no central cyanosis. She was in sinus rhythm with a blood pressure of $160 / 80 \mathrm{~mm} \mathrm{Hg}$, normal venous pressure, and mild bilateral ankle oedema. The apex beat was displaced laterally, and normal heart sounds were accompanied by a soft full length diastolic murmur heard maximally at the apex but also readily heard widely over the precordium and beneath the left clavicle. Chest expansion was good and auscultation revealed vesicular breath sounds with no added sounds. There was smooth firm hepatomegaly to $3 \mathrm{~cm}$ below the right costal margin; the splenic tip was just palpable but ascites was not detected.

A chest radiograph confirmed cardiomegaly (car-

Requests for reprints to Dr N G Dewhurst, Department of Cardiology, The Royal Infirmary, Lauriston Place, Edinburgh EH3 9YW. diothoracic ratio 0.63 ) with prominence of the pulmonary arteries and increased vascular markings (fig 1). The electrocardiogram showed sinus rhythm and normal axis and PR interval, with $T$ wave inversion in the inferior leads. In addition there was an $S$ wave in lead III of $12 \mathrm{~mm}$ and an $R$ wave in V1 of $4 \mathrm{~mm}$. Forced expiratory volume in one second was 1.4 litres with a vital capacity of 2 litres (ratio $70 \%$ ). Cross sectional ultrasound examination

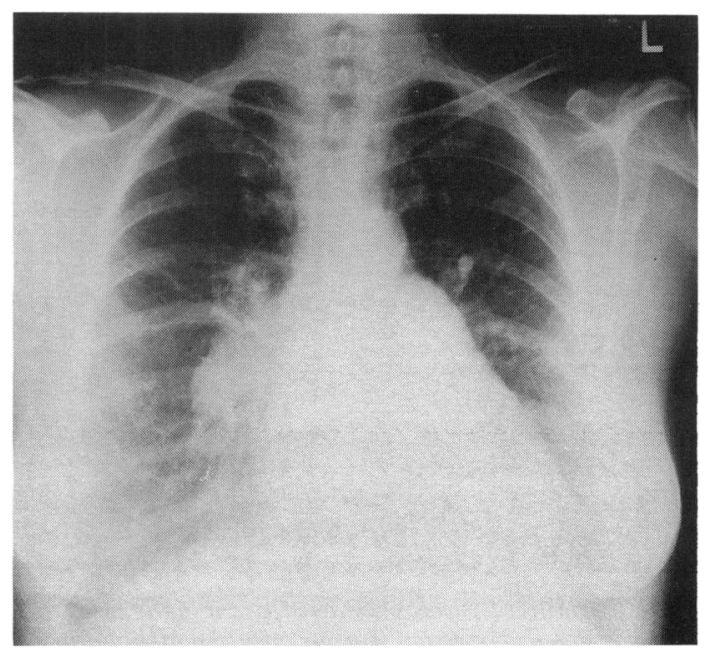

Fig 1 Chest radiography in posteroanterior projection showing cardiomegaly and prominent main pulmonary arteries. 
showed thin mobile mitral leaflets, normal left ventricular function, and there were no echocardiographic or Doppler features of valve regurgitation.

She was admitted for further investigation. The platelet count was reduced at $60 \times 10^{9}$ per litre. Prolongation of the prothrombin time ratio $(1 \cdot 7: 1)$ was attributed to hepatic disease. Systemic arterial blood gas analysis when she was breathing air showed a $\mathrm{Po}_{2}$ of $10 \cdot 1 \mathrm{kPa}$ and a $\mathrm{PcO}_{2}$ of $4 \cdot 1 \mathrm{kPa}$. Full lung volumes and gas transfer were normal. An isotope perfusion lung scan with $\mathrm{Tc}^{99 \mathrm{~m}}$ macroaggregates showed no evidence of pulmonary emboli and she was referred for cardiac catheterisation. Pressures were: right atrium mean 8 , right ventricle $65 / 0-10$, pulmonary artery $65 / 30$, pulmonary artery wedge $20 / 5$ (mean 10 ), left ventricle $120 / 8-20$, and aorta $120 / 60 \mathrm{~mm} \mathrm{Hg}$. Simultaneous pressure recordings showed no clinically significant gradient across the mitral valve. Pulmonary arterial oxygen saturation was $60 \%$; oximetry showed no left to right shunt and the aortic saturation was $89 \%$. Left ventricular angiography revealed hyperdynamic ventricular function and a very tortuous dilated left coronary system. There was no mitral regurgitation. Selective coronary angiography showed multiple fistulas between a grossly dilated left anterior descending coronary artery and left ventricle (fig 2). The circumflex artery was also enlarged but no definite fistulous communication was evident. The

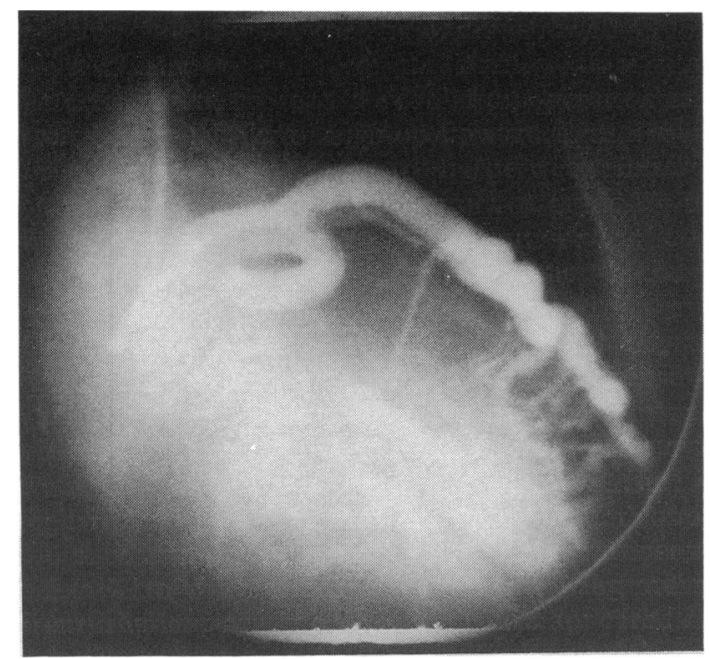

Fig 2 Selective left coronary arteriogram in the right anterior oblique projection showing aneurysmal dilatation of the circumflex and anterior descending coronary arteries. There are multiple fistulous communications between the distal portion of the left anterior descending artery and the left ventricle, providing a simultaneous left ventriculogram. right coronary artery was of normal size and appearance. Right heart catheterisation with pulmonary angiography was repeated 10 weeks later. On this occasion the pulmonary artery pressure was $105 / 40$ (mean 60$) \mathrm{mm} \mathrm{Hg}$. Pulmonary angiography demonstrated markedly dilated central pulmonary arteries. The branches did not show pronounced tapering and no intraluminal filling defects were seen.

\section{Discussion}

Congenital coronary arterial fistulas are rare in the general population but they have been reported in 0.2 per cent of patients undergoing coronary arteriography and are more common in individuals with other forms of congenital heart disease. ${ }^{1}$ Similar fistulas have been reported after penetrating or blunt chest injury. ${ }^{2}$ There was no such history in our patient. An association with congenital hepatic fibrosis has not been described before but patients with this disease and the associated renal polycystic disease are at risk of arterial malformation; particularly the development of berry aneurysm. ${ }^{3}$ The affected coronary artery is frequently aneurysmal and $90 \%$ of fistulas drain via a single channel into the right heart, producing a continuous murmur. ${ }^{4}$ Congenital fistulas between the left anterior descending coronary artery and the left ventricle have been described before in only three cases. ${ }^{56}$ Our case was unusual because there were multiple tortuous channels. Dyspnoea is a common presenting symptom but signs of frank heart failure are unusual at presentation. ${ }^{5}$

Pulmonary hypertension has also been reported, but only in patients with fistulas draining into the right ventricle. ${ }^{78}$ In our case no single definite cause for pulmonary hypertension could be established. Obesity and obstructive airways disease were contributory factors but they were unlikely to have been totally responsible for the degree of pulmonary hypertension observed. Cirrhosis, however, can be associated with a form of pulmonary hypertension that has pathological features resembling primary pulmonary hypertension. A considerable increase in pulmonary arterial pressure was reported in $0.25 \%$ of individuals with hepatic cirrhosis of alcoholic origin but the precise cause for this is unknown. ${ }^{9}$ There is little evidence that thromboembolic disease was a primary cause of the hypertension. A more likely explanation is that a vasoconstrictive agent reached the pulmonary circulation as a result of failure of hepatic detoxification. If the assumed toxin was produced or released by the splanchnic territory it would explain why portal-systemic shunting during operation increases the risk of pulmonary hypertension in cirrhotic patients. 
Early ligation is recommended for uncomplicated single coronary fistulas because the risks of heart failure, endocarditis, dissection, myocardial infarction, and rupture are considerable and increase with age. ${ }^{45}$ Because of clotting abnormalities and the multiple fistulous channels operation was not advised in our case.

\section{References}

1 Wenger NK. Rare causes of coronary heart disease. In: Hurst JW, ed. The heart. New York: McGraw-Hill, 1978:1348-9.

2 Morgan JR, Forker AD, O'Sullivan MJ, Fosburg RG. Coronary arterial fistulas. Am J Cardiol 1972;30: 432-6.
3 Brain WR. Diseases of the nervous system. 8th ed. Oxford: University Press, 1977:352-3.

4 Liberthson RK, Sagar K, Berkoben JP, Weintraub RM, Levine FH. Congenital coronary arteriovenous fistula. Circulation 1979;59:849-54.

5 Urrutia CO, Falaschi G, Oh DA, Cooley DA. Surgical management of 56 patients with congenital coronary artery fistulas. Ann Thorac Surg 1983;35:300-7.

6 Arani DT, Greene DG, Klocke FJ. Coronary artery fistulas emptying into left heart chambers. Am Heart $J$ 1978;96:438-43.

7 Neill C, Mounsey P. Auscultation in patent ductus arteriosus with a description of two fistulae simulating patent ductus. Br Heart J 1958;20:61-75.

8 Oldham HN, Ebert PA, Young WG, Sabiston DC. Surgical management of congenital coronary artery fistula. Ann Thorac Surg 1971;12:503-11.

9 Lebrec D, Capron JP, Dhumeaux D, Benhamou JP. Pulmonary hypertension complicating portal hypertension. Am Rev Respir Dis 1979;120:849-56. 